\title{
DAMPAK SISTEM DRAINASE PEMBANGUNAN PERUMAHAN GRAHA NATURA TERHADAP SALURAN LONTAR, KECAMATAN SAMBIKEREP, SURABAYA
}

\author{
Rangga Adi Sabrang, Edijatno DEA, Fifi Sofia \\ Jurusan Teknik Sipil, Fakultas Tenik Sipil dan Perencanaan Intitut Teknologi Sepuluh November \\ Jl. Arief Rahman Hakim, Surabaya 60111 \\ E-mail : ranggaadis@gmail.com, edijatno@ce.its.ac.id, fifi@ce.its.ac.id
}

\begin{abstract}
Abstrak - Dengan adanya pembangunan perumahan Graha Natura di kawasan jalan Sambikerep-Kuwukan, kelurahan Lontar, kecamatan Sambikerep Surabaya, yang dulunya kawasan ini adalah perkebunan otomatis akan mempengaruhi kondisi sistem drainase di sekitar wilayah tersebut. Perubahan jumlah limpasan air hujan akan menjadi tolok ukur pertama yang harus diperhatikan dan dikelola dengan baik. Untuk mengatasi terjadinya penambahan volume debit limpasan dari kawasan perumahan tersebut, maka kapasitas saluran Lontar dari sekitar kawasan tersebut harus diketahui. Hal ini bertujuan untuk mengetahui apakah saluran pembuang tersebut masih mampu menampung debit limpasan air setelah ditambah dengan debit limpasan air akibat pembangunan perumahan Graha Natura.

Maka dari itu dalam pengerjaan Tugas Akhir ini diperlukan peninjauan secara langsung di lapangan tepatnya di kawasan tersebut dan di sekitarnya, hal ini dilakukan untuk mengetahui kondisi kawasan tersebut dan saluransaluran pembuangnya. Setelah itu dilakukan suatu perumusan masalah dari pembangunan perumahan di kawasan tersebut, dari kawasan perkebunan menjadi perumahan tentu akan menimbulkan beberapa masalah diantara dampak perubahan koefisien pengaliran di kawasan, rencana jaringan drainase, kondisi kapasitas saluran eksisting sebelum dan sesudah pembangunan perumahan, kondisi jaringan drainase di luar kawasan perumahan, dan operasional bosem beserta pintu air dan pompanya. Dari rumusan masalah tersebut selanjutnya dilakukan pengumpulan beberapa data, antara lain data hidrologi, data hidrolika, dan data topografi kawasan tersebut. Setelah itu dilakukan analisa hidrologi meliputi analisa data curah hujan, dan perhitungan debit rencana. Serta yang terakhir melakukan analisa hidrolika yang meliputi perencanaan dimensi saluran perumahan, perhitungan volume limpasan dari perumahan, perhitungan kapasitas bosem, dan perhitungan kapasitas saluran Lontar.

Hasil dari analisa limpasan kawasan perumahan Graha Natura, mengalami peningkatan dari 6322,23 m3 menjadi 10676 m3 dengan waktu hujan 2 jam. Sedangkan saluran Sambikerep melimpaskan 4398,40 m3 dengan waktu 2 jam juga. Bosem mampu menerima kedua limpasan tersebut, tetapi untuk waktu hujan lebih dari 2 jam bosem tidak mampu menerima limpasannya. Dampak dari limpasan tersebut juga berpengaruh pada saluran Lontar, dengan debit limpasan dari outlet pintu air bosem sebesar 1,26 m3/det perlu dilakukan normalisasi di beberapa potongan melintang saluran Lontar.
\end{abstract}

Kata kunci : Perumahan Graha Natura Sambikerep Surabaya, Sistem Drainase Perumahan

Saluran Lontar adalah saluran pembuang

\section{PENDAHULUAN}

Pembangunan perumahan Graha Natura di kawasan jalan Sambikerep-Kuwukan, kelurahan Lontar, kecamatan Sambikerep Surabaya, memiliki luas total lahan sebesar $339.832,00 \mathrm{~m}^{2}$. Dulunya lahan ini merupakan daerah perkebunan, dan sebagian daerah rawa-rawa. Pembangunan perumahan di kawasan tersebut masih mencapai 30\% dan sisanya masih berupa lahan kosong yang siap dibangun rumah-rumah. Dengan pembangunan perumahan di wilayah tersebut, otomatis akan mempengaruhi kondisi sistem drainase di sekitar wilayah tersebut. Perubahan jumlah limpasan air akan menjadi

tolok ukur pertama yang harus diperhatikan dan dikelola dengan baik. eksisting dari kawasan perumahan Graha Natura, sebelumnya limpasan air hujan ditampung di bosem terlebih dahulu sebelum dibuang ke saluran Lontar, bosem memiliki 2 inlet yaitu inlet dari saluran Baru dan saluran Sambikerep. Untuk saluran Sambikerep memiliki 2 cabang saluran dengan limpasan dari kawasan luar, cabang saluran pertama air dibuang langsung ke saluran Lontar dan cabang saluran yang kedua air dibuang ke bosem. Untuk saluran Baru limpasan air dari kawasan akan langsung dibuang ke bosem. Dari bosem tersebut tidak semua air limpasan yang masuk akan ditampung, setelah itu akan dibuang ke saluran Lontar baik secara gravitasi maupun pompa. Untuk mengatasi terjadinya penambahan volume debit limpasan, maka kapasitas saluran pembuang eksisting tersebut harus diketahui. Hal ini bertujuan untuk mengetahui apakah saluran 
pembuang masih mampu menampung debit limpasan air setelah ditambah dengan debit limpasan air akibat pembangunan perumahan Graha Natura. Oleh karena itu, sebaiknya limpasan air yang ada di area perumahan dapat ditahan dan ditampung sebanyak mungkin pada bosem, agar tidak terlalu membebani saluran pembuang Lontar. Apabila saluran pembuang Lontar tidak mencukupi dapat dilakukan normalisasi saluran atau pengaturan debit pada outlet bosem.

Tujuan rencana pembangunan perumahan Graha Natura yang berada di wilayah kelurahan Lontar, kecamatan Sambikerep, kota Surabaya adalah:

Untuk memenuhi kebutuhan fasilitas hunian berupa permukiman yang dilengkapi dengan fasilitas pendukungnya seperti ruko, lapangan olah raga, tempat ibadah dan lain-lain, sehingga memberikan kenyamanan pada penghuninya dan menjadi satu kesatuan tidak terpisahkan dari kegiatan perumahan itu sendiri.

Terciptanya penataan ruang yang sesuai dengan arahan Rencana Tata Ruang Wilayah Kota Surabaya berdasar Perda No 3 tahun 2007.

Meningkatkan perekonomian wilayah secara tidak langsung melalui kegiatan ruko yang tersedia di kawasan Perumahan Graha Natura sebagai fasilitas pendukung perumahan tersebut.

Perumahan Graha Natura Sambikerep Surabaya memiliki perincian penggunaan lahan sebagai berikut :

Perdagangan /jasa komersial : $\quad 60.074,80 \mathrm{~m}^{2}$

Perumahan $: 136.271,30 \mathrm{~m}^{2}$

Fasilitas um. Pengembang : $5.104,35 \mathrm{~m}^{2}$

Fasilitas Umum Pemkot $\quad: \quad 19.836,50 \mathrm{~m}^{2}$

Ruang Terbuka Hijau (RTH) : $21.239,05 \mathrm{~m}^{2}$

Bosem

$7.161,55 \mathrm{~m}^{2}$

Jalan Dan Saluran

Total

$\frac{: 90.144,45 \mathrm{~m}^{2}}{: 339.832,00 \mathrm{~m}^{2}}$

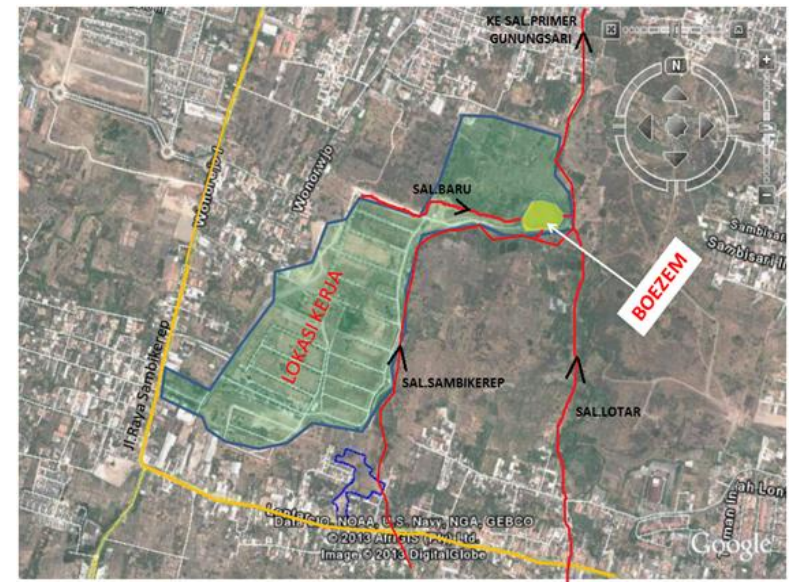

Hal 30

\section{Gambar 1. Lokasi Pembangunan Perumahan Graha Natura}

\section{METODOLOGI}

Langkah - langkah pengerjaan Tugas Akhir ini akan dilakukan sesuai diagram alir pada Gambar 2.1. Untuk lebih detailnya bisa dilihat pada buku tugas akhir ini pada Bab III.

\section{A. Studi Literatur}

Mempelajari buku-buku literatur dan laporanlaporan data yang terkait dengan wilayah studi untuk mendapatkan informasi yang lebih mendetail mengenai kawasan lahan.

\section{B. Studi Lapangan}

Tahapan ini merupakan peninjauan secara langsung ke lapangan tepatnya di kawasan perumahan Graha Natura dan sekitarnya. Hal ini dilakukan untuk mengetahui keadaan eksisting saluran yang nantinya akan dilakukan perhitungan.

Mencari tahu data ukur saluran Lontar.

Mencari informasi tentang saluran eksisting Lontar dan tata guna lahan kawasan luar.

\section{Pengumpulan Data}

Pengumpulan data dilakukan untuk membantu jalannya studi, data yang dikumpulkan meliputi data primer dan sekunder, data primer diambil langsung dari studi lapangan yaitu dimensi saluran Sambikerep, saluran Baru dan saluran Lontar.

Data sekunder diambil dari data instansi terkait, literatur dan laporan dan topik sejenis sebagai berikut :

- Data curah hujan stasiun Kandangan

- Peta kontur kawasan perumahan Graha Natura dan di sekitar

- Siteplan kawasan perumahan Graha Natura

- Surabaya Drainase Master Plan (daerah kelurahan Lontar)

- Rencana Tata Ruang Wilayah (RTRW)

\section{Tahap Analisa Perencanaan}

- Analisa Hidrologi

- Analisa Hidrolika 


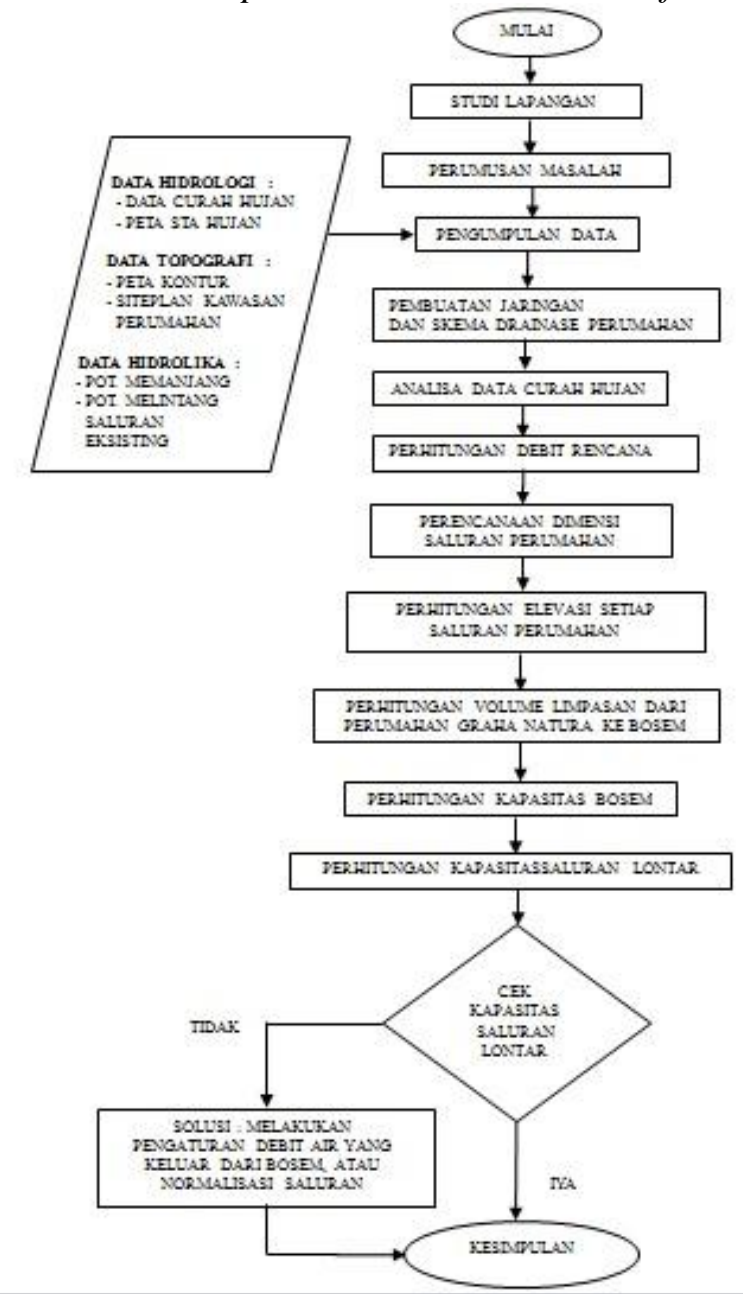

Gambar 2.1 Langkah Penyelesaian Tugas Akhir

\section{HASIL PEMBAHASAN}

\section{Analisa Data Curah Hujan}

Data curah hujan harian yang tersedia sebanyak 20 tahun (1994-2013), data ini terlebih dahulu dilakukan analisa perhitungan nilai hujan ratarata sebelum dilakukan perhitungan statistik. Data hujan pada perencanaan sistem drainase kawasan perumahan Graha Natura ini berasal dari satu buah stasiun pengamatan, yaitu stasiun hujan Kandangan.

\section{Analisa Distribusi Probabilitas}

Untuk mencari tinggi hujan rencana periode ulang tertentu dilakukanlah analisa distribusi probabilitas. Dalam analisa distribusi probabilitas ini, dilakukan dengan empat metode distribusi, yaitu metode Gumbel, Normal, Log Normal, dan Log Pearson Type III. Adapun hasil dari perhitungan dapat dilihat pada tabel berikut :
Tabel 3.1. Nilai tinggi hujan rencana periode ulang dari masing-masing analisa distribusi probabilitas.

\begin{tabular}{|l|c|c|c|c|}
\hline \multirow{2}{*}{} & \multicolumn{4}{|c|}{ Distribusi Probabilitas } \\
\cline { 2 - 5 } & Gumbel & Normal & $\begin{array}{c}\text { Log } \\
\text { Normal }\end{array}$ & $\begin{array}{c}\text { Log Pearson Type } \\
\text { III }\end{array}$ \\
\hline $\mathrm{X}_{2}(\mathrm{~mm})$ & 93,021 & 92,944 & 92,325 & 92,411 \\
\hline $\mathrm{X}_{5}(\mathrm{~mm})$ & 128,570 & 125,980 & 121,338 & 121,338 \\
\hline $\mathrm{X}_{10}(\mathrm{~mm})$ & 152,142 & 140,663 & 139,315 & 139,315 \\
\hline
\end{tabular}

*Sumber : Hasil Perhitungan

\section{Uji Kecocokan Distribusi Probabilitas}

Uji kecocokan ini bertujuan untuk mengecek apakah hasil dari distribusi probabilitas dapat diterima atau tidak untuk perhitungan lebih lanjut. Dapat dilakukan dengan dua metode yaitu metode Chi-Kuadrat dan Smirnov Kolmogorof. Hasil perhitungan dapat dilihat pada tabel berikut :

Tabel 3.2. Nilai uji kecocokan chi-kuadrat dan smirnov kolmogorof

\begin{tabular}{|l|c|c|}
\multicolumn{1}{c|}{ Smirnov kolmogorof } \\
\cline { 2 - 3 } \multirow{2}{*}{ Persamaan } & \multicolumn{2}{|c|}{ Uji Kecocokan } \\
\cline { 2 - 3 } \multicolumn{1}{|c|}{ Distribusi } & Chi-Kuadrat & Smirnov Kolmogorof \\
\cline { 2 - 3 } & $\mathrm{DK}=3, \alpha=5 \%$ & $\mathrm{n}=20, \alpha=5 \%$ \\
\hline Gumbel & $7.0<7.815$ & $0.156<0.29$ \\
\hline Normal & $7.0<7.816$ & $0.139<0.29$ \\
\hline Log Normal & $3.4<7.817$ & $0.102<0.29$ \\
\hline Log Pearson Type III & $2.2<7.818$ & $0.086<0.29$ \\
\hline
\end{tabular}

*Sumber : Hasil Perhitungan

\section{Perhitungan Dimensi Saluran}

Perhitungan dimensi saluran drainase pada kawasan perumahan Graha Natura dihitung dalam satu DAS yang dibagi beberapa Sub-DAS, antara lain kavling/rumah, jalan, dan taman. Tinggi hujan periode ulang yang dipakai adalah tinggi hujan periode ulang 2 tahun $\left(\mathrm{R}_{2}\right)$. Perencanaan dimensi saluran ini terdiri dari beberapa jenis saluran yaitu saluran tersier, sekunder, dan primer, yang akan direncanakan dengan dimensi yang sama/typical. Untuk mendimensi saluran kawasan perumahan ini, dilakukan analisa cara coba-coba dengan acuan selisih dari debit hidrolika dan debit hidrologi mendekati nol. Setelah setiap dimensi saluran diketahui maka direncanakan dimensi yang typical sesuai dengan jenis salurannya (tersier, sekunder, primer).

Tabel 3.3. Hasil perhitungan dimensi saluran perumahan

\begin{tabular}{|c|c|c|c|c|c|c|}
\hline No & Bentuk & Jenis & Lebar & Tinggi Air & Tinggi Jagaan & Tinggi Total \\
& Saluran & Saluran & $(\mathrm{m})$ & $(\mathrm{m})$ & $(\mathrm{m})$ & $(\mathrm{m})$ \\
\hline 1 & Persegi & Tersier & 0.8 & 0.5 & 0.2 & 0.7 \\
\hline 2 & Persegi & Sekunder & 1.6 & 0.7 & 0.2 & 0.9 \\
\hline 3 & Persegi & Primer & 2.0 & 0.8 & 0.2 & 1.0 \\
\hline
\end{tabular}


*Sumber : Hasil Perhitungan

\section{Analisa Limpasan Hujan ke Bosem}

Pada bosem terdapat dua inlet limpasan air yaitu yang berasal dari saluran Baru dan percabangan saluran Sambikerep, sehingga diharapkan hanya $50 \%$ limpasan saja yang masuk dari cabang saluran Sambikerep. Sedangkan outlet bosem ini membuang limpasan air ke saluran Lontar. Analisa hidrograf bosem dimaksudkan untuk mengetahui berapa besar debit dan volume limpasan air yang dapat diterima oleh bosem tersebut, serta berapa debit dan volume limpasan air yang mampu dibuang ke saluran Lontar dengan melihat kapasitas yang mampu diterima saluran Lontar.

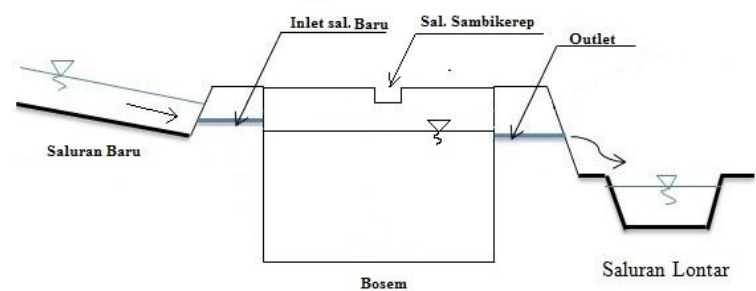

Gambar 2. Kondisi bosem pada saat tampungan penuh

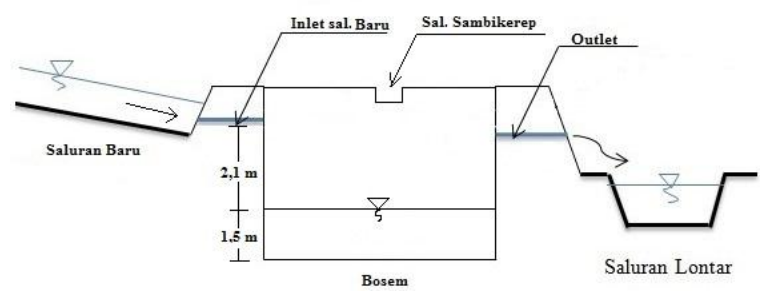

Gambar 3. Kondisi bosem dengan tampungan air tanah

Keadaan bosem diambil pada saat musim hujan dengan volume tampungan yang sudah ada dari air tanah sebesar 10742,32 $\mathrm{m}^{3}$ dengan ketinggian genangan $1,5 \mathrm{~m}$ dari dasar bosem, volume tampungan yang sudah ada tersebut berasal dari keadaan air tanah di kawasan tersebut dan air hujan yang jatuh langsung dari atas bosem. Berikut adalah analisa perhitungan hidrograf untuk bosem :

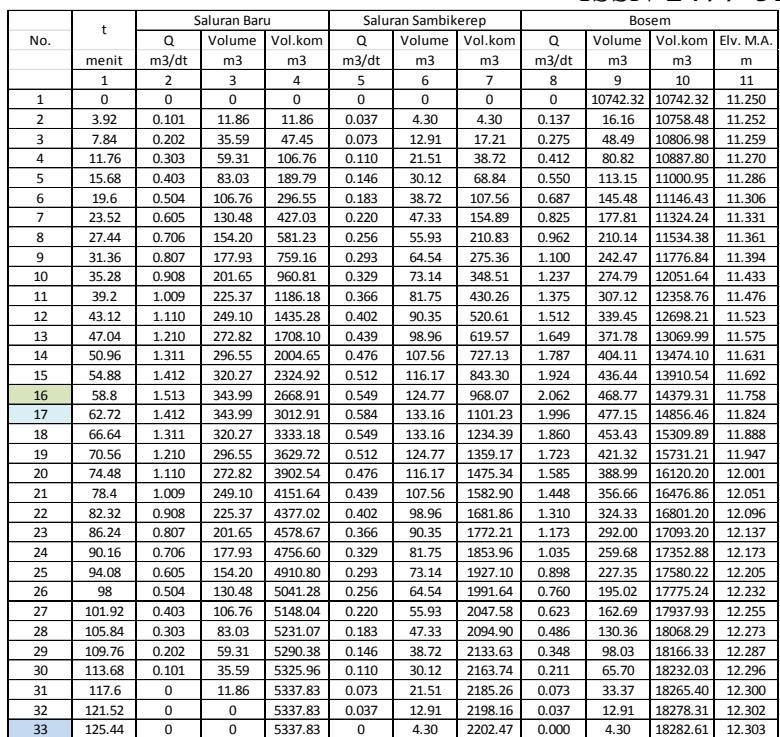

*Sumber : Hasil Perhitungan

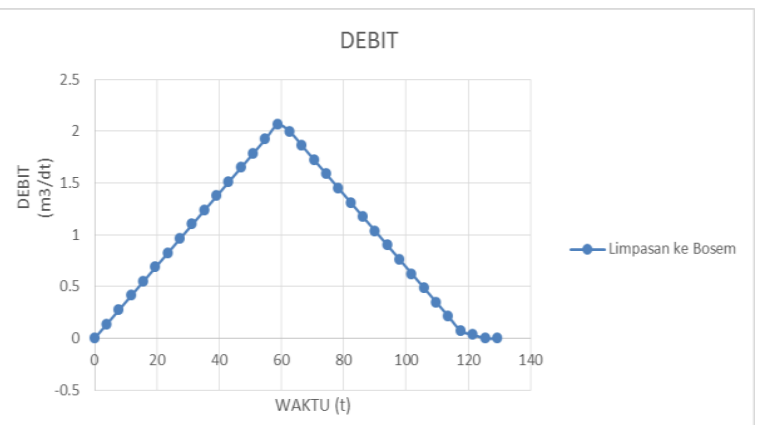

Gambar 3. Grafik debit limpasan dari saluran Baru dan Sambikerep ke bosem $(t c=$ td).

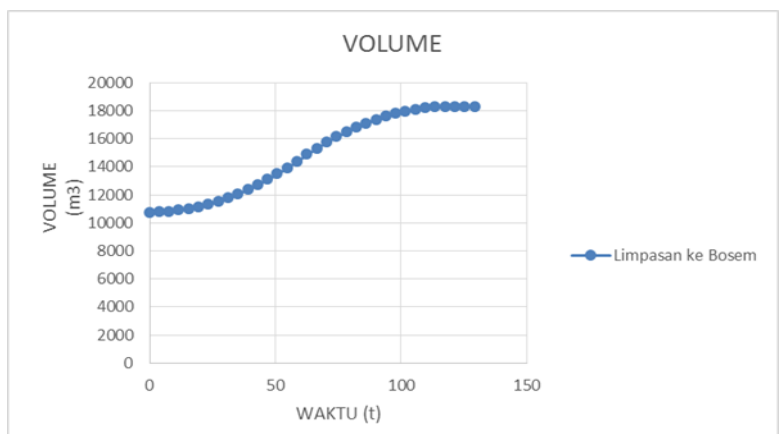

Gambar 4. Grafik volume limpasan dari saluran Baru dan Sambikerep ke bosem $(t c=$ td).

Tabel 3.5. Perhitungan hidrograf limpasan td = 2.tc dari saluran Baru dan 50\% limpasan dari saluran Sambikerep.

Tabel 3.4. Perhitungan hidrograf limpasan $t d=t c$ dari saluran Baru dan 50\% limpasan dari saluran Sambikerep. 
Perencanaan Pipa Transmisi dalam Pemanfaatan Sumber Mata Air Umbulan untuk Kota Surabaya

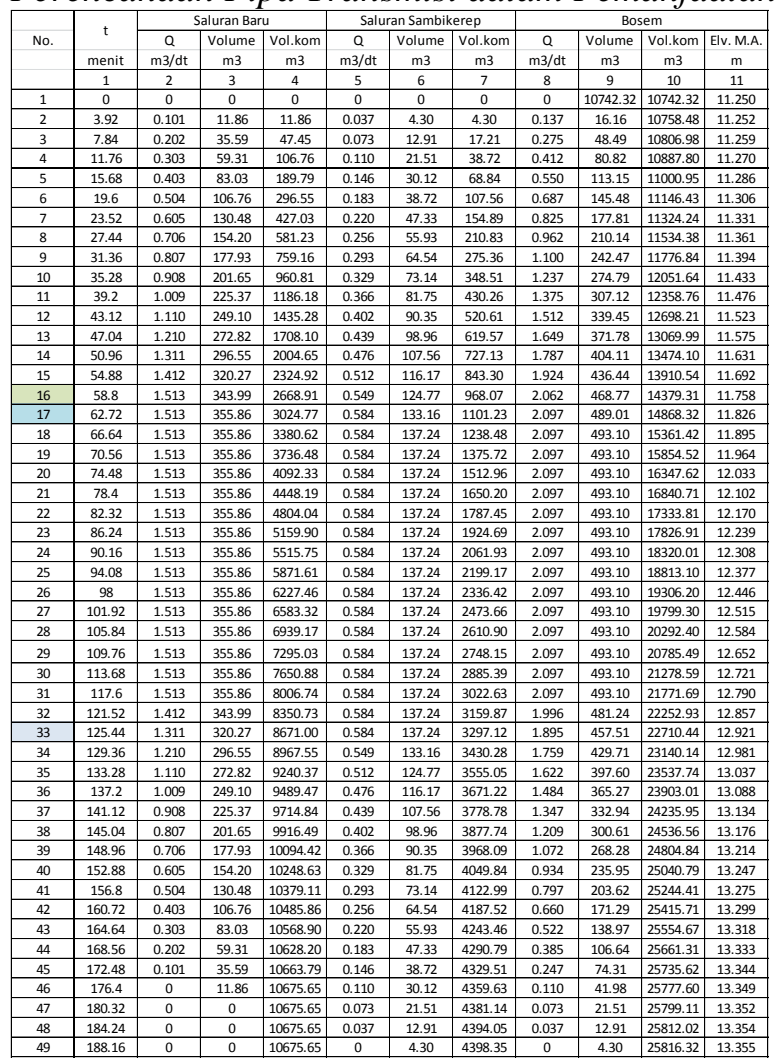

*Sumber : Hasil Perhitungan

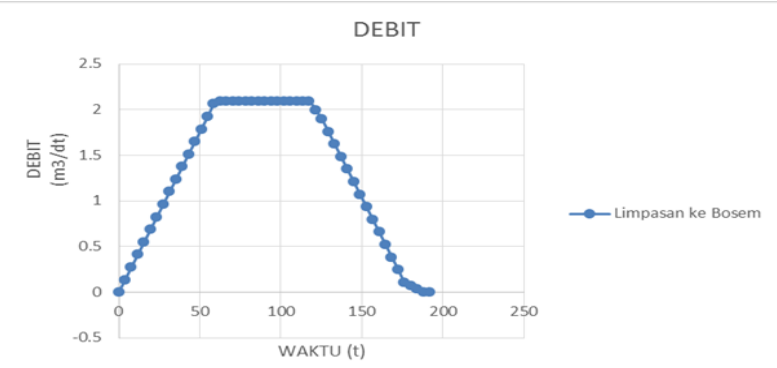

Gambar 5. Grafik debit limpasan dari saluran Baru dan Sambikerep ke bosem (2.tc $=\mathbf{t d}$ ).

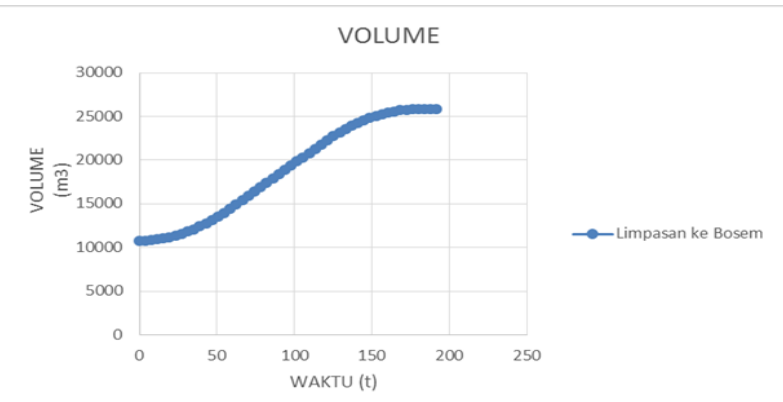

Gambar 6. Grafik volume limpasan dari saluran Baru dan Sambikerep ke bosem (2.tc $=\mathbf{t d}$ ).

Dari analisa perhitungan di atas diperoleh hasil sebagai berikut :

\section{Tabel 3.6. Hasil perhitungan hidrograf limpasan yang masuk ke bosem.}

\begin{tabular}{|c|c|c|c|c|}
\hline No & $\begin{array}{c}\text { Waktu Lama Hujan }(\mathrm{td}) \\
(\text { menit) }\end{array}$ & $\begin{array}{c}\text { Volume } \\
(\mathrm{m} 3)\end{array}$ & $\begin{array}{c}\text { Elevasi M.A Bosem } \\
(\mathrm{m})\end{array}$ & Keterangan \\
\hline 1 & $\mathrm{td}=\mathrm{tc}=60$ menit & 7540.29 & 12.303 & Aman \\
\hline 2 & $\mathrm{td}=2 . \mathrm{td}=120$ menit & 15074.00 & 13.355 & Aman \\
\hline 3 & $\mathrm{td}=130$ menit & 16102.34 & 13.550 & Meluap \\
\hline
\end{tabular}

*Sumber : Hasil Perhitungan

\section{Analisa Pintu Air}

Bosem memiliki keterbatasan volume oleh karena itu volume air yang berada di bosem harus dibuang ke saluran pembuang Lontar. Pintu air digunakan pada saat air masih bisa dibuang dengan gravitasi dari outlet bosem. Selain pada outlet bosem pintu air juga direncanakan di inlet bosem yang menghubungkan dengan cabang saluran Sambikerep, untuk membagi limpasan sebesar $50 \%$ dari limpasan total saluran Sambikerep. Bukaan pintu air direncanakan berdasarkan batasan debit yang keluar pada outlet dan yang masuk pada inlet saluran Sambikerep.

Tabel 3.7. Perhitungan pintu air pada outlet bosem

\begin{tabular}{|c|c|c|c|c|c|c|c|c|}
\hline No. & $\begin{array}{c}\text { Elv } \mathbf{M . A} \text { Bosem } \\
(\mathbf{m})\end{array}$ & $\begin{array}{c}\text { Elv dasar outlet } \\
(\mathbf{m})\end{array}$ & $\begin{array}{c}\mathbf{h} \\
(\mathbf{m})\end{array}$ & $\begin{array}{c}\mathbf{b} \\
(\mathbf{m})\end{array}$ & $\mathbf{\mu}$ & $\begin{array}{c}\mathbf{a} \\
(\mathbf{m})\end{array}$ & $\begin{array}{c}\mathbf{g} \\
(\mathbf{m} \mathbf{2} \text { det })\end{array}$ & $\begin{array}{c}\mathbf{Q} \\
(\mathbf{m} \mathbf{3} / \text { det })\end{array}$ \\
\hline $\mathbf{1}$ & $\mathbf{2}$ & $\mathbf{3}$ & $\mathbf{4}$ & $\mathbf{5}$ & $\mathbf{6}$ & $\mathbf{7}$ & $\mathbf{8}$ & $\mathbf{9}$ \\
\hline 1 & 12.921 & 12.850 & 0.071 & 1.0 & 0.8 & 0.5 & 9.81 & 0.47 \\
\hline 2 & 12.981 & 12.850 & 0.131 & 1.0 & 0.8 & 0.5 & 9.81 & 0.64 \\
\hline 3 & 13.037 & 12.850 & 0.187 & 1.0 & 0.8 & 0.5 & 9.81 & 0.77 \\
\hline 4 & 13.088 & 12.850 & 0.238 & 1.0 & 0.8 & 0.5 & 9.81 & 0.86 \\
\hline 5 & 13.134 & 12.850 & 0.284 & 1.0 & 0.8 & 0.5 & 9.81 & 0.94 \\
\hline 6 & 13.176 & 12.850 & 0.326 & 1.0 & 0.8 & 0.5 & 9.81 & 1.01 \\
\hline 7 & 13.214 & 12.850 & 0.364 & 1.0 & 0.8 & 0.5 & 9.81 & 1.07 \\
\hline 8 & 13.247 & 12.850 & 0.397 & 1.0 & 0.8 & 0.5 & 9.81 & 1.12 \\
\hline 9 & 13.275 & 12.850 & 0.425 & 1.0 & 0.8 & 0.5 & 9.81 & 1.16 \\
\hline 10 & 13.299 & 12.850 & 0.449 & 1.0 & 0.8 & 0.5 & 9.81 & 1.19 \\
\hline 11 & 13.318 & 12.850 & 0.468 & 1.0 & 0.8 & 0.5 & 9.81 & 1.21 \\
\hline 12 & 13.333 & 12.850 & 0.483 & 1.0 & 0.8 & 0.5 & 9.81 & 1.23 \\
\hline 13 & 13.344 & 12.850 & 0.494 & 1.0 & 0.8 & 0.5 & 9.81 & 1.24 \\
\hline 14 & 13.349 & 12.850 & 0.499 & 1.0 & 0.8 & 0.5 & 9.81 & 1.25 \\
\hline 15 & 13.352 & 12.850 & 0.502 & 1.0 & 0.8 & 0.5 & 9.81 & 1.26 \\
\hline 16 & 13.354 & 12.850 & 0.504 & 1.0 & 0.8 & 0.5 & 9.81 & 1.26 \\
\hline 17 & 13.355 & 12.850 & 0.505 & 1.0 & 0.8 & 0.5 & 9.81 & 1.26 \\
\hline 18 & 13.355 & 12.850 & 0.505 & 1.0 & 0.8 & 0.5 & 9.81 & 1.26 \\
\hline
\end{tabular}

*Sumber : Hasil Perhitungan

\section{Analisa Pompa Air}

Pada saat pembuangan air pada bosem tidak dapat dilakukan secara gravitasi, maka untuk mengatasinya diperlukan pompa air. Karena kapasitas tampungan bosem yang besar diperlukan juga kapasitas pompa yang besar pula untuk mempercepat waktu pengurasan, tetapi tetap harus melihat kapasitas saluran pembuang Lontar apakah mampu menerima debit pompanya. Direncanakan memakai pompa dengan kapasitas $0,2 \mathrm{~m}^{3} /$ det sebanyak 3 buah, 2 buah untuk pengoperasian langsung di outlet bosem dan 1 buah untuk cadangan. 


\section{Analisa Saluran Lontar}

Saluran Lontar adalah saluran pembuang eksisting kawasan perumahan Graha Natura dan kawasan sekitarnya, saluran ini merupakan saluran yang masih alami dengan DAS perumahan Graha Natura dan kawasan perkebunan di sekitarnya. Ada 10 titik tinjau pada saluran Lontar yaitu potongan P1 sampai P10 dengan data ukur potongan melintang yang berbeda-beda. Berikut adalah perhitungan kapasitas saluran Lontar dan dampak dari penambahan limpasan bosem perumahan Graha Natura:

Tabel 3.8. Perhitungan kapasitas saluran Lontar

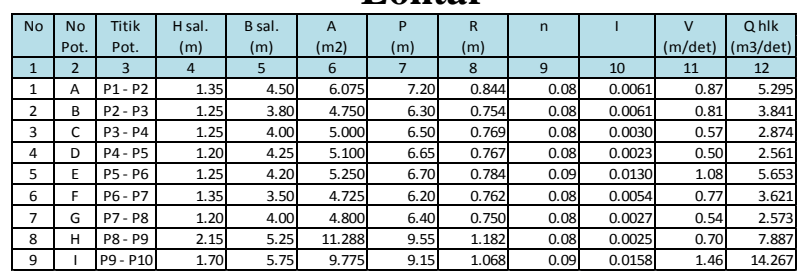

*Sumber : Hasil Perhitungan

Tabel 3.9. Dimensi saluran Lontar dengan debit limpasan kawasan luar

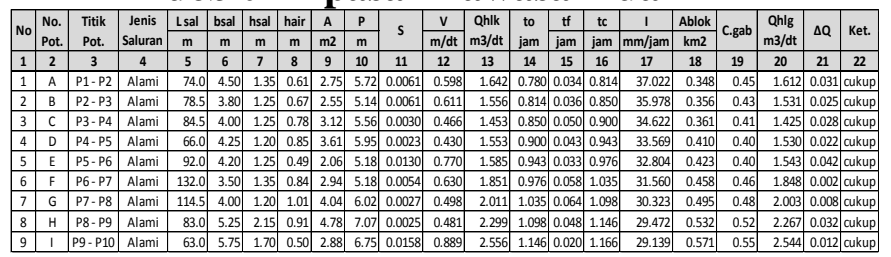

*Sumber : Hasil Perhitungan

Tabel 3.10. Dimensi saluran Lontar dengan debit limpasan kawasan luar + debit limpasan pompa air bosem

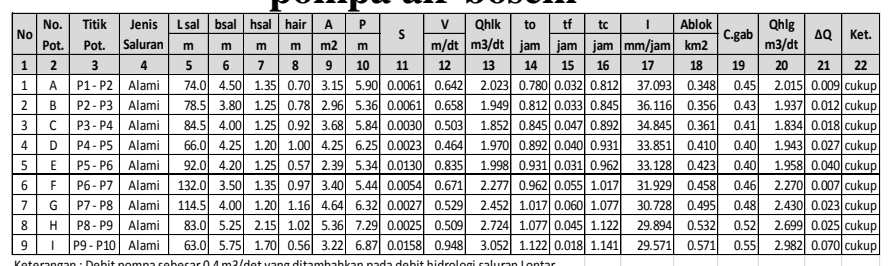

*Sumber : Hasil Perhitungan

\section{saluran Lontar dengan debit limpasan kawasan luar + debit limpasan pintu air bosem}

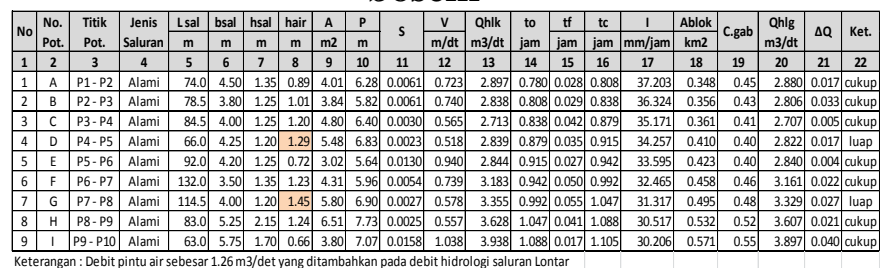

*Sumber : Hasil Perhitungan
Tabel 3.12. Normalisasi dimensi saluran Lontar dengan debit limpasan kawasan luar + debit limpasan pintu air bosem

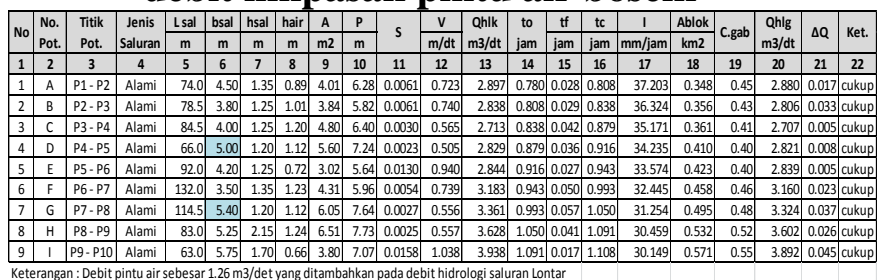

*Sumber : Hasil Perhitungan

\section{KESIMPULAN}

Dari hasil yang diperoleh melalui analisa perhitungan, maka dapat diambil kesimpulan :

1. Perubahan tata guna lahan dari koefisien pengaliran $\mathrm{C}=0,2$ yang awalnya perkebunan menjadi perumahan dengan koefisien pengaliran $\mathrm{C}=0,6$. Sehingga dengan perubahan tata guna lahan tersebut mengakibatkan perubahan volume limpasan air dari $6322,23 \mathrm{~m}^{3}$ menjadi $18966,7 \mathrm{~m}^{3}$.

2. Dengan tinggi hujan periode ulang 2 tahun sebesar 93,02 mm, saluran Baru melimpaskan debit sebesar $1,51 \mathrm{~m}^{3} /$ det dari perumahan Graha Natura, sedangkan saluran Sambikerep melimpaskan debit sebesar 1,16 $\mathrm{m}^{3} /$ det dari tata guna lahan yang akan dibangun di masa mendatang (sebagian pemukiman, dan sebagian masih perkebunan).

3. Di dalam sistem jaringan drainase perumahan Graha Natura terdapat 162 saluran drainase, yaitu 1 saluran primer, 8 saluran sekunder, 153 saluran tersier.

4. Kemampuan bosem dalam menerima limpasan air hujan hingga $t d=2 \cdot t c=2$ jam dengan volume limpasan sebesar $15074 \mathrm{~m}^{3}$, dengan menerima 50\% limpasan dari cabang saluran Sambikerep yang masuk ke bosem, sebelumnya keadaan bosem sudah menerima resapan air tanah sebesar 10742,32 $\mathrm{m}^{3}$. Sedangkan untuk limpasan hujan td $>2$ jam bosem tidak mampu lagi menerima limpasannya.

5. Operasional bosem mula-mula limpasan dibiarkan hingga elevasi muka air pada bosem mencapai elevasi dasar outlet +12.85 , pada saat ketinggian elevasi sudah melebihi +12.85 pintu air dibuka untuk membuang air dalam bosem hingga elevasi kembali turun ke +12.85 , ketika elevasi sudah kembali ke 
Perencanaan Pipa Transmisi dalam Pemanfaatan Sumber Mata Air Umbulan untuk Kota Surabaya

+12.85 pembuangan air tidak bisa dilakukan secara gravitasi, sehingga pompa air mulai dinyalakan hingga mencapai elevasi muka air tanah +11.25 .

6. Waktu pengurasan bosem pada limpasan hujan $\mathrm{tc}=\mathrm{td}=1$ jam hanya bisa dilakukan dengan pengoperasian pompa, yaitu selama 5,23 jam. Sedangkan pada limpasan hujan td $=2 \cdot \mathrm{tc}=2 \mathrm{jam}$ pengurasan bosem dapat dilakukan dengan pintu air dan pompa, yaitu selama 9,02 jam.

7. Kondisi kapasitas saluran Lontar terjadi luapan pada beberapa potongan melintangnya yaitu potongan P4-P5 dan P7P8 karena bertambahnya limpasan air dari outlet bosem, dengan debit terbesar dari pintu air bosem sebesar $1,26 \mathrm{~m}^{3} /$ det.

\section{Saran}

1. Dilakukan normalisasi saluran Lontar dengan melebarkan salurannya terutama pada potongan-potongan melintang saluran Lontar yang terjadi luapan akibat limpasan dari kawasan luar dan outlet bosem. Potongan saluran yang perlu dilebarkan yaitu potongan:

a. P4-P5 dengan dimensi normalisasi 5,00 $\mathrm{m} \times 1,20 \mathrm{~m}$ dan kapasitas debit 2,82 $\mathrm{m}^{3} /$ det.

b. P7-P8 dengan dimensi normalisasi 5,40 $\mathrm{m} \times 1,20 \mathrm{~m}$ dan kapasitas debit 3,32 $\mathrm{m}^{3} /$ det.

2. Apabila tidak menormalisasi saluran Lontar, dapat dilakukan pengaturan debit yang keluar pada pintu air bosem yaitu dengan membuang debit $<1,26 \mathrm{~m}^{3} /$ det, sehingga menghasilkan debit limpasan dari bosem yang tidak terlalu membebani saluran Lontar. (2 alternatif a dan $b$ ini hanya berlaku untuk limpasan hujan $\mathrm{td}=2 . \mathrm{tc}=2 \mathrm{jam}$ ).

\section{DAFTAR PUSTAKA}

[1] Kamiana, I Made. 2010. Teknik Perhitungan Debit Rencana Bangunan Air. Palangkaraya. Graha Ilmu.

[2] Maryono, Agus. 2001. Hidrolika Terapan. Yogyakarta. Pradnya Paramita.

[3] Mawardi Erman, Moch. Memed. 2006. Desain Hidrolik Bendung Tetap. Bandung. Alfabeta.

[4] Mulyanto. 2012. Penataan Drainase Perkotaan. Semarang. Graha Ilmu.

[5] Pengairan, Dirjen. 1986. Kriteria Perencanaan-02. Jakarta. Departemen Pekerjaan Umum.

[6] Setiyo, Titien. 2013. Laporan Kajian Drainase Perumahan Graha Natura. Surabaya. CV Asfinda Teknika Konsultan.

[7] Seyhan, Ersin. 2008. Dasar-dasar Hidrologi. Yogyakarta. Gadjah Mada University Press.

[8] Sofia, Fifi. 2006. Modul Ajar Drainase. Surabaya. Teknik Sipil ITS.

[9] Surabaya, P. 2012. Surabaya Drainage Master Plan 2012-2018. Surabaya.

[10] Suripin. 2004. Sistem Drainase Perkotaan yang Berkelanjutan. Yogyakarta. Andi. 